\title{
Long noncoding RNAs as Organizers of Nuclear Architecture
}

\author{
Lu Cheng, Hui Ming, Minzhe Zhu \& Bo Wen* \\ Department of Biochemistry and Molecular Biology and Key Laboratory of Metabolism and Molecular Medicine of Ministry of Education \& \\ Institutes of Biomedical Sciences, Shanghai Medical College, Fudan University, Shanghai 200032, China \\ Received July 17, 2015; accepted September 6, 2015; published online January 27, 2016
}

\begin{abstract}
In the eukaryotic cell nucleus, chromatin and its associated macromolecules must be organized into a higher-ordered conformation to function normally. However, mechanisms underlying the organization and dynamics of the nucleus remain unclear. Long noncoding RNAs (lncRNAs), i.e., transcripts longer than 200 nucleotides with little or no protein-coding capacity, are increasingly recognized as important regulators in diverse biological processes. Recent studies have shown that some lncRNAs are involved in various aspects of genome organization, including the facilitation of chromosomal interactions and establishment of nuclear bodies, suggesting that lncRNAs act as general organizers of the nuclear architecture. Here, we discuss recent advances in this emerging and intriguing field.
\end{abstract}

long noncoding RNAs, chromatin, nuclear architecture

Citation: Cheng, L., Ming, H., Zhu, M., and Wen, B. (2016). Long noncoding RNAs as Organizers of Nuclear Architecture. Sci China Life Sci 59, $236-244$. doi: $10.1007 / \mathrm{s} 11427-016-5012-\mathrm{y}$

\section{INTRODUCTION}

The eukaryotic genome is not linear, but packed into a three-dimensional (3D) confirmation to execute its function. In the interphase nucleus, chromatin forms higher-order structures, such as inter (intra)-chromosomal loops and macro-scale chromatin domains (Bickmore, 2013). Furthermore, DNA, RNA, and proteins can be assembled into non-membranous and highly dynamic nuclear bodies, including the nucleolus, nuclear speckle, paraspeckle, and etc. (Sleeman and Trinkle-Mulcahy, 2014). Meanwhile, the positioning of chromatin and regulatory factors is not random, but is associated with specific nuclear compartments, such as the nuclear periphery (Cremer and Cremer, 2010). This well-patterned nuclear architecture is essential to coordinate the regulation of genome functions. However, mechanisms underlying the formation and maintenance of the nuclear architecture, and its dynamics in development

*Corresponding author (email: bowen75@fudan.edu.cn) and diseases remain poorly understood.

For a long time, biological research has taken cues from the central dogma and focused on protein-coding genes. However, with rapid advances in functional genomics, it has become clear that only $\sim 1.5 \%$ of the human genome encodes proteins, whereas $70 \%-90 \%$ of the genome can be transcribed into many kinds of non-coding RNAs (Consortium, 2012; Kapranov et al., 2007; Okazaki et al., 2002). Among these, the long non-coding RNAs (lncRNAs), which are longer than 200 nucleotides, have received a great deal of attention, and thousands of lncRNAs have been identified in the past few years. These lncRNAs show strong spatial and temporal expression specificity, and are involved in diverse biological processes via interactions with other biological molecules, including proteins, DNA, messenger RNAs (mRNAs), and microRNAs (Guttman and Rinn, 2012; Lee, 2012; Rinn and Chang, 2012; Song et al., 2014).

Decades ago, it was noted that the digestion or inhibition of nuclear RNAs leads to the disruption of chromatin organization (Nickerson et al., 1989). In addition, a tran- 
scriptome analysis indicated that lncRNAs are highly enriched in the nucleus (Cheng et al., 2005). Subsequent studies have identified some lncRNAs, such as Xist and Neat1, as key regulators of nuclear organization. Recent evidence has demonstrated that lncRNAs may serve as general organizers in many aspects of nuclear architecture (Batista and Chang, 2013). Here, we discuss advances in this emerging and intriguing field.

\section{IncRNAs MEDIATE CHROMATIN INTERACTIONS}

In interphase cell nuclei, chromatin domains interact extensively within or across chromosomes. Enhancer-promoter interactions are recognized as an important mechanism to regulate gene expression. Some lncRNAs have recently been found to participate in interactions at different levels of chromatin organization (Figure 1).

\section{Intra-chromosomal interactions}

Enhancers are intergenic or intragenic DNA regulatory elements, and are crucial to control spatiotemporal gene expression during development. Enhancers can be bound with activators and marked with specific histone modifications, including $\mathrm{H} 3 \mathrm{~K} 4 \mathrm{me} 1$, H3K27ac, and H3K9ac. Recently, a new category of lncRNAs transcribed from active enhancers was identified, and these enhancer-templated non-coding RNAs (eRNAs) are positively associated with their neighboring protein-coding genes (De Santa et al., 2010; Kim et al., 2010; Wang et al., 2011a). For example, in human macrophages treated with endotoxin or breast cancer cells treated with estradiol, after eRNAs were induced, the transcription of their target genes is activated (De Santa et al., 2010; Hah et al., 2013). Recent studies have also identified a series of eRNAs involved in the regulation of immune processes and inflammatory responses (Hah et al., 2015; Ne et al., 2014). Interestingly, a class of lncRNAs shows enhancer-like functions, although they are not necessarily transcribed from enhancers (Orom et al., 2010).

Several studies have proposed that eRNAs or lncRNAs may facilitate chromosome looping between enhancers and their target promoters (Figure 1A). For example, in estradiol-treated MCF7 cells, DNA loops can be induced between enhancers and promoters as detected by a 3D-DSL (3D DNA selection and ligation) assay or ChIA-PET (chromatin interaction analysis by paired-end tag sequencing), and the down-regulation of eRNAs reduces the looping and the expression of its target genes (Hah et al., 2013; Li et al., 2013). Similarly, ncRNA-a elements interact with mediator complexes and activates expression via looping with its target genes (Lai et al., 2013). However, a recent study indicated that eRNAs do not affect enhancer-promoter interactions, but act as decoy for the negative elongation factor (NELF) to activate the expression of nearby genes in neurons (Schaukowitch et al., 2014), suggesting multiple mechanisms of eRNAs.

In addition to eRNAs, other kinds of lncRNAs are involved in intra-chromosomal interactions. The lncRNA HOTTIP, located at the $5^{\prime}$ end of the HoxA (homeobox A) cluster, was reported to contact target genes via chromosome looping, and initiates $\mathrm{H} 3 \mathrm{~K} 4 \mathrm{me} 3$ modifications by interacting with the WDR5/MLL complex. This IncRNA is necessary and sufficient to activate the transcription of adjacent HoxA genes, although the overall chromatin conformation is not affected by its depletion (Wang et al., 2011b). A recent study based on chromatin conformation capture technology (3C) found that the $5^{\prime}$ end of the lncRNA Kcnq1ot1 mediates the formation of long-range chromosomal looping between KvDMR1 and the Kcn1q1 promoter, and maintains allele-specific silencing of Kcn1q1 by recruiting EZH2, a methyltransferase of $\mathrm{H} 3 \mathrm{~K} 7 \mathrm{me} 3$. Decreased Kcn1q1ot1 expression disturbs the formation of chromosome loops and results in a loss of Kenq1 imprinting (Zhang et al., 2014). Recently, Xiang et al. identified a IncRNA, CCAT1-L, expressed from a super enhancer $515 \mathrm{~kb}$ upstream of MYC (Xiang et al., 2014). CCAT1-L is required for the long-range interaction between this super enhancer and a MYC promoter via an interaction with CTCF, a key organizer of the genome (Xiang et al., 2014). Therefore, the formation of long-range intra-chromosomal looping should be a general mechanism by which lncRNAs regulate chromatin status.
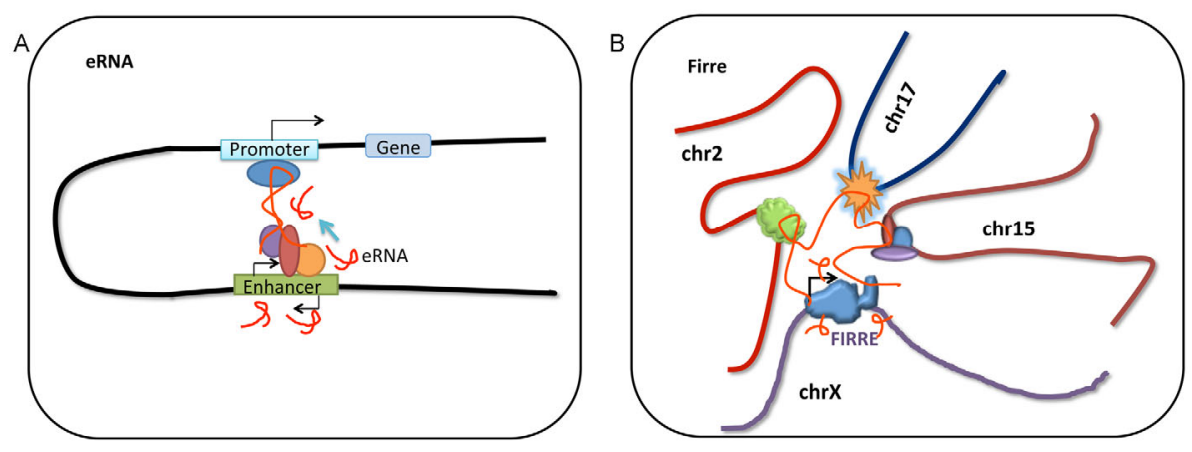

Figure 1 Long noncoding RNAs (lncRNAs) facilitate chromosomal interactions. A, Enhancer-templated non-coding RNAs (eRNAs) are involved in enhancer-promoter interactions. B, Firre forms an inter-chromosomal compartment to co-regulate transcriptional activation. 


\section{Inter-chromosomal interactions}

Long-range chromosomal interactions occur not only within the same chromosome, but also among a plurality of loci on different chromosomes, which are organized in specific nuclear compartments and regulated by common factors. Recently, the lncRNA Firre (functional intergenic repeating RNA element) has been shown to organize multiple chromosomes to establish a nuclear domain (Hacisuleyman et al., 2014). Firre was initially discovered in a screen of functional lncRNAs during adipogenesis (Sun et al., 2013). It is an $\mathrm{X}$-chromosome transcribed, 5.8-kb lncRNA containing 156-bp repeating sequences that form the secondary structure. Firre interacts with the nuclear matrix factor hnRNPU via its repeating domains, and coats 5-MB chromatin regions of the $\mathrm{X}$ chromosome in cis. In addition to its cis-acting role, Firre also acts in trans on loci from at least five different chromosomes, including chromosomes 2, 9, 15, and 17. These sites include many genes related to energy metabolism. Importantly, either the depletion of Firre or the knockdown of hnRNPU leads to a loss of these trans-chromosomal interacting loci (Hacisuleyman et al., 2014). These data demonstrated that Firre affects nuclear architecture by mediating inter-chromosomal interactions. Although the case of Firre provided evidence that inter-chromosomal interactions are mediated by lncRNAs, the proposed mechanism needs to be proven by additional investigations of other lncRNAs.

\section{IncRNAs ARE RELATED TO NUCLEAR BODIES}

The eukaryotic cell nucleus is compartmentalized to coordinate cellular processes, such as RNA synthesis and processing, DNA replication, and ribosome subunit assembly. Relatively well-characterized nuclear bodies include the nucleolus, nuclear speckle, paraspeckle, PML (promyelocytic leukemia protein) body, Cajal body and etc. These bodies are highly dynamic, and their biological roles are still not fully known. LncRNAs are associated with the function of nuclear bodies, and some (such as Neat1 and IGS) play crucial roles in establishing and maintaining these bodies (Figure 2).

\section{Neat1 and paraspeckles}

The paraspeckle is a kind of sub-nuclear structure near the nuclear speckle with a typical size of approximately $0.5 \mu \mathrm{m}$, and each cell contains about 10-20 paraspeckles (Fox et al., 2002). It exists in almost all cell types, except for human embryonic stem (ES) cells (Chen and Carmichael, 2009). The main function of the paraspeckle is to retain mRNAs with adenosine to inosine modifications in the nucleus, thereby regulating the expression level of these genes (Fox these mRNAs usually contain Alu elements in humans and type B1 and B2 inverted repeat elements in mice. The key and Lamond, 2010). The 3' UTRs (untranslated regions) of

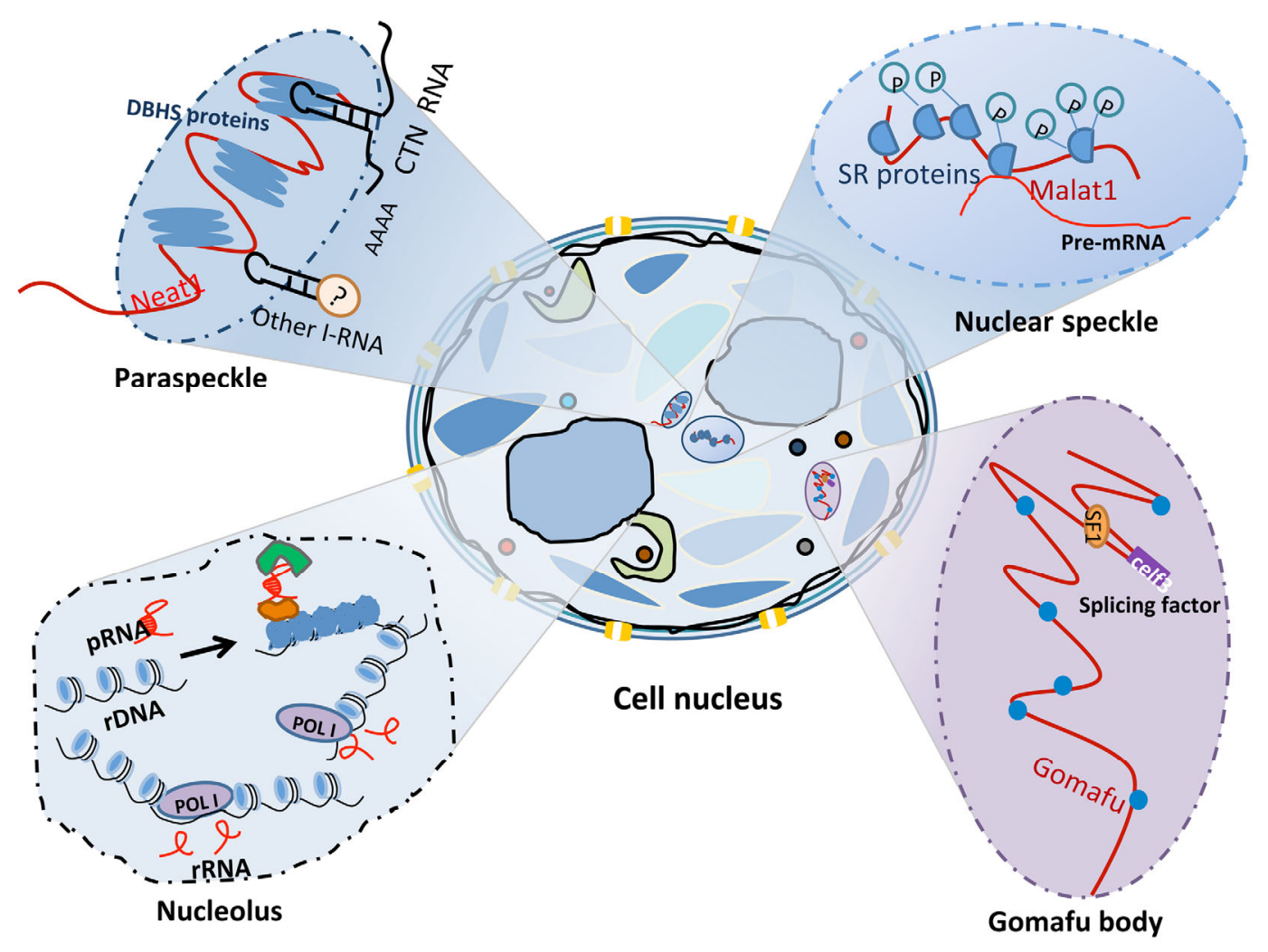

Figure 2 LncRNAs participate in the organization of nuclear bodies. The cartoon represents the landscape of an interphase mammalian cell nucleus. The four well-characterized nuclear bodies described are the paraspeckle, nuclear speckle, Gomafu body, and nucleolus. 
components of the paraspeckle include the proteins PSPC1 (paraspeckle protein1), SFPQ (splicing factor, proline- and glutamine-rich), and NONO (non-POU domain-containing octamer-binding protein), which share about $50 \%$ sequence identity within two N-terminal RNP-type RNA recognition motifs and a C-terminal coiled-coil domain, and the lncRNA Neat1 (nuclear-enriched abundant transcript 1) (Bond and Fox, 2009).

Neat1 is conserved in mammals and has two isoforms in both humans and mice, Neat1-1 and Neat1-2 (Men $\varepsilon$ and Men $\beta$ in mice), which are 3.7 and $22.7 \mathrm{~kb}$ (3.2 and $20.7 \mathrm{~kb}$ in mice), respectively (Guru et al., 1997). Treating cells with RNase destroys paraspeckles, which suggests that its structural integrity depends on the presence of specific RNAs (Fox et al., 2005). A number of gain- and loss-offunction studies further demonstrated that Neat 1 is essential for the establishment and maintenance of paraspeckles (Clemson et al., 2009; Sasaki et al., 2009; Shevtsov and Dundr, 2011; Sunwoo et al., 2009) via scaffolding core proteins, i.e., NONO, SFPQ, and PSPC1 (Sasaki et al., 2009; Souquere et al., 2010). Interestingly, these processes are dependent on the transcriptional activity of Neat1, as transcription inhibition prevents the establishment of new paraspeckles, even though Neat1 RNA is abundant (Mao et al., 2011).

Unexpectedly, Neat1 knockout mice do not show obvious phenotypes, except for the abolishment of paraspeckles, which suggests that the paraspeckle is nonessential for normal life activities in mice, but is involved in the response to stimuli or stress (Nakagawa et al., 2011). Furthermore, after treatment with a proteasome inhibitor, the size of the paraspeckle increases due to the upregulation of Neat1 transcription (Hirose et al., 2014), and tumor hypoxia induces paraspeckles by activating Neat1 expression (Choudhry et al., 2014), indicating that the paraspeckle is a pressure-responsive nuclear substructure. However, two other investigations have revealed that Neat1 and paraspeckles are required for mammary gland development and lactation (Standaert et al., 2014) and are associated with the early phase of amyotrophic lateral sclerosis (Nishimoto et al., 2013). A recent study reported that the transfection of 20-mer phosphorothioate-modified antisense oligonucleotides can recruit core proteins to form paraspeckle-like foci in the absence of Neat1 RNA (Shen et al., 2014), suggesting a general mechanism of nucleic acid-mediated nuclear body formation.

\section{pRNA and the nucleolus}

As the site of ribosomal RNA synthesis and subunit assembly, the nucleolus is probably the most well known nuclear domain. Under specific stimuli, lncRNAs can be induced from large intergenic spacers (IGS) of rDNA clusters, and these IGS lncRNAs act as decoys to retain selected proteins, including VHL, Hsp70, and MDM2/PML, into the nucleo- lus (Audas et al., 2012).

Interestingly, the IGS IncRNA and its interacting proteins form a large subnucleolar structure named the detention center (DC), and the formation of the DC is dependent on the expression of IGS IncRNA (Jacob et al., 2013). A recent report has revealed that the maturation of pRNA, originated from the processing of an IGS lncRNA, is required for the establishment of heterochromatin at ribosomal RNA genes during ES cell differentiation (Savic et al., 2014). These data suggested that IncRNA regulates the structure and function of the nucleolus under environmental stimuli and during development.

\section{Malat1 and nuclear speckles}

The lncRNA Malat1 (metastasis-associated lung adenocarcinoma transcript 1) was originally identified in non-small cell lung cancer cells ( $\mathrm{Ji}$ et al., 2003). It is transcribed from the human genome at a locus $58 \mathrm{~kb}$ downstream of Neat1, known as Neat2 (nuclear enriched abundant transcript 2) (Hutchinson et al., 2007). Similar to Neat1, Malat1 is ubiquitously expressed and is one of the most abundant lncRNAs in the nucleus owing to its stable structure (Hutchinson et al., 2007; Zhang et al., 2012). Furthermore, Malat 1 is evolutionarily conserved in vertebrates, especially its $3^{\prime}$ end, with up to $90 \%$ similarity between humans and mice (Ulitsky et al., 2011). In humans, the 8.5-kb transcript of Malat1 is processed by various ribonucleases to form a tRNA-like 61-nt small RNA at the 3' end called mascRNA, which is transported out of the nucleus (Affymetrix and Cold Spring Harbor Laboratory, 2009; Wilusz et al., 2008). The large, 6.7-kb fragment is retained in the nucleus and enriched in nuclear speckles (Hutchinson et al., 2007).

Nuclear speckles are highly dynamic nuclear domains, which are composed of various precursor mRNAs (premRNA) and splicing factors. Studies have shown that Malat1 in nuclear speckles are involved in mRNA modification and splicing by recruiting a variety of pre-mRNA splicing factors to the activation sites (Tripathi et al., 2010). Although Malat1 regulates gene expression in nuclear speckles, it is not essential for the formation or maintenance of nuclear speckles, which is different from Neat1. Down-regulation of Malat1 does not affect the expression or localization of nuclear speckle markers (Hutchinson et al., 2007; Nakagawa et al., 2012; Tripathi et al., 2010). According to some studies, Malat1 reduction can cause a series of phenotypic changes, including apoptosis and cell cycle progression (Tripathi et al., 2010; Tripathi et al., 2013). Surprisingly, three Malat1 knockout studies have shown no obvious phenotypic defects (Eissmann et al., 2012; Nakagawa et al., 2012; Zhang et al., 2012), and the deletion of Malat1 does not have a direct impact on RNA splicing. Only two of these studies have suggested that Malat1 knockout has a slight impact on the expression of adjacent genes, including Neat1. Although Malat1 is a well-studied lncRNA and has broad physiological functions, particularly in tumorigenesis 
(Gutschner et al., 2013a; Gutschner et al., 2013b; Ji et al., 2014), the detailed molecular mechanisms underlying these functions have yet to be uncovered.

\section{Gomafu}

Another lncRNA related to nuclear domain formation is Gomafu, also known as MIAT (myocardial infarction associated transcript) or RNCR2 (retinal non-coding RNA 2) (Ishii et al., 2006; Sone et al., 2007). Gomafu is a 9-kb IncRNA located in the nucleus, and has more than 10 alternative isoforms. Unlike Neat1 and Malat1, which are expressed ubiquitously, Gomafu is only expressed in some cells of the fetal rat brain and adult nervous system, although it is conserved in amphibians, birds, and mammals (Rapicavoli et al., 2010; Tsuiji et al., 2011).

Gomafu RNA has been detected as discrete dots in the nucleus, which do not colocalize with any known nuclear bodies. Interestingly, the formation and maintenance of this new kind of nuclear domain are not dependent on transcriptional activity, unlike paraspeckles and nuclear speckles (Sone et al., 2007). It has been found that a chicken homo$\log$ of Gomafu contains multiple "UACUAAC" tandem repeats, a conserved intron branch sequence in Saccharomyces cerevisiae, which bind splicing factor SF1 (splicing factor 1) in vivo or in vitro (Tsuiji et al., 2011). Although the interaction between Gomafu and SF1 is not necessary for its localization, Gomafu might affect splicing by interactions with splicing factors, similar to Malat1. A recent study confirmed that Gomafu binds the splicing factors QKI (quaking homolog, KH domain RNA binding protein) and SRSF1 (serine/arginine-rich splicing factor 1), and dysregulation of Gomafu leads to inaccurate alternative splicing patterns, which are the same as those observed in schizophrenia (Barry et al., 2014). Although the lncRNA Gomafu may represent a novel model for IncRNA-mediated regulation of nuclear architecture, its molecular mechanisms need further studies.

\section{X-CHROMOSOME INACTIVATION: AN EXAMPLE OF COORDINATED REGULATION OF NUCLEAR ARCHITECTURE BY IncRNAs}

In mammals, to balance the expression level of X-linked genes between males and females, one $\mathrm{X}$ chromosome in female cells is silenced randomly. X-chromosome inactivation (XCI) is a highly complicated and coordinated process that is controlled by a series of lncRNAs transcribed from the X-inactivation center (Xic), including Xist, Tsix, Jpx, and Ftx (Gendrel and Heard, 2014; Lee, 2012). Briefly, $\mathrm{Xist}$, the key regulator of XCI, coats the entire X-chromosome and recruits polycomb protein complex 2 (PRC2) to induce repressive and condensed chromatin. Then, the inactivated X-chromosome aggregates to a nuclear domain named the Barr body, and is positioned near the nuclear membrane (Figure 3).

An earlier study demonstrated that ectopic expression of Xist in chromosome 12 induces chromosome-wide inactivation (Lee and Jaenisch, 1997). A recent study has shown that inserting inducible XIST to one copy of chromosome 21 (Chr21) in Down's syndrome pluripotent stem cells causes the entire chromosome to be coated and inactivated by XIST (Jiang et al., 2013). These results indicate that Xist is sufficient to initiate the inactivation of its transcribed chromosome. In undifferentiated mouse ES cells, both

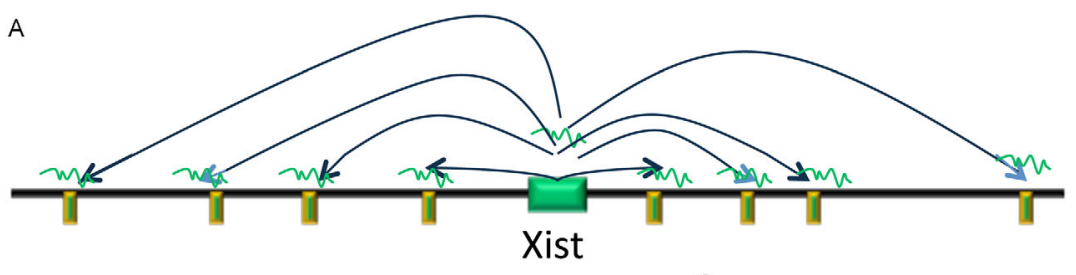

B

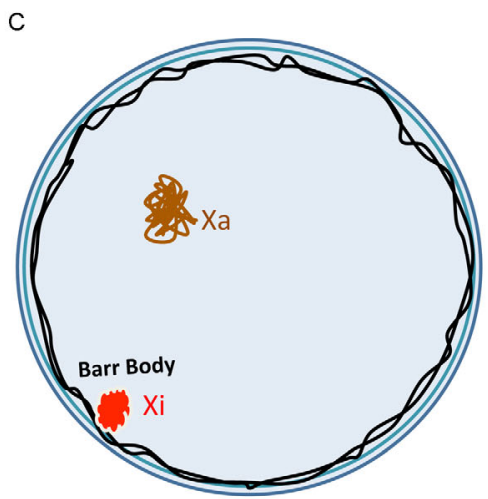

Figure 3 Xist controls $\mathrm{X}$ chromosome inactivation by reshaping nuclear architecture. A, Xist is transcribed from the X-inactivation center (green) and spread to the entire chromosome. B, Xist searches for targets based on the 3D chromatin conformation. C, Inactivated X chromosome forms a Barr body and is localized to the nuclear periphery. 
$\mathrm{X}$-chromosomes remain active, and the expression of Xist is extremely low. Pluripotent factors, such as Oct4, Nanog, and Rex 1 and the IncRNA Tsix inhibit the expression of Xist in ES cells; upon differentiation, Xist is immediately activated and expressed from the future inactive $\mathrm{X}$ chromosome (Gendrel and Heard, 2014). In mouse embryonic development from the 4-cell stage to preimplantation, $\mathrm{XCI}$ is imprinted to inactivate the paternal X chromosome. After implantation, both $\mathrm{X}$ chromosomes will be reactivated in the cells of the inner cell mass, and, subsequently, one chromosome will be inactivated randomly. Studies have shown that these two XCI processes may rely on different mechanisms, which are not fully understood.

Two recent studies have analyzed chromatin targets of Xist globally using hybridization-based purification (Engreitz et al., 2013; Simon et al., 2013); they showed that Xist identifies its targets by exploiting the 3D conformation of the $\mathrm{X}$ chromosome, rather than by searching for specific sequences (Engreitz et al., 2013; Simon et al., 2013). Simon et al. further demonstrated that Xist spreads on the X chromosome following a two-step mechanism: first, to gene-rich islands and then to gene-poor regions. It should be noted that these studies were based on large cell populations and the data are average patterns for millions of cells. A recent paper explored the ultrastructure of the Barr body at the single-cell level, using 3D super-resolution microscopy (Smeets et al., 2014). They found that there are less than 100 distinct Xist RNA foci in a Barr body, which are enriched on the boundaries of collapsed active nuclear compartments, suggesting a non-uniform "coating" of Xist on the inactive X chromosome (Smeets et al., 2014). These controversial results highlight the importance of comparing and integrating data from high-throughput and single-cell assays.

\section{OUTLOOK}

In summary, recent advances have demonstrated that some lncRNAs are involved in multiple aspects of nuclear architecture, but the list remains short. Although thousands of IncRNAs have been identified, their functions and underling mechanisms need to be elucidated. One interesting direction is to explore their potential involvement in nuclear architecture under various physiological or pathological conditions. For example, the lncRNA VAD, which belongs to the recently discovered very long intergenic ncRNAs (vlincRNAs) (St Laurent et al., 2013), is required to maintain oncogene-induced senescence (Lazorthes et al., 2015). VAD activates the master gene INK4 in trans, presumably by promoting the removal of repressive H2A.Z at this locus (Lazorthes et al., 2015). Additional investigations are needed to detect potential physical trans interactions involving VAD.

Furthermore, as the nucleus is highly dynamic, it would be interesting to investigate lncRNAs involved in nuclear dynamics. As an example, the lncRNA TERRA (telomeric repeat-containing RNA) plays critical roles in the maintenance of telomerase activity and homeostasis of chromosome ends (Cusanelli and Chartrand, 2015). Intriguingly, St Laurent et al. proposed a theory that darker matter RNAs (including lncRNAs) act as "intelligent scaffolds" in establishing dynamic and reversible nuclear micro-domains and in differentially binding other macro-molecules to modulate nuclear processes, such as epigenetic signaling (St Laurent et al., 2012). Experimental evidence is needed to evaluate this interesting hypothesis.

However, methodological imperfections are still a major limitation in this field. More reliable and user-friendly techniques need to be developed to detect RNA interactions with DNA/RNA/proteins, the spatial localization of low-abundance RNAs, the structures of IncRNA complexes, etc (Zhang et al., 2015; Zhu et al., 2013). For example, to detect chromatin interactions, conformation capture-based assays (HiC, ChIA-PET, etc.) and hybridization-based methods (such as ChIRP (chromatin isolation by RNA purification) and RAP (RNA antisense purification)) require large numbers of cells. Thus, the results represent the averages of millions of cells, and do not reflect the variability among cells. Currently developed super-resolution microscopy combined with 3D-FISH can be used to detect nuclear architecture at the single cell level, thus providing complementary data to high-throughput assays (Smeets et al., 2014). Moreover, given the general roles of lncRNA as "organizers" (Rinn and Chang, 2012), current strategies, which mainly come from studies of coding genes, need to be improved accordingly (Yin et al., 2015). In light of current studies, lncRNAs could act as general regulators of nuclear architecture, although many mysteries need to be uncovered.

Compliance and ethics The author(s) declare that they have no conflict of interest.

Acknowledgements This work was supported by the National Basic Research Program of China (2011CBA01100; 2015CB943000), National Natural Science Foundation of China (31371296, 91019001), Shanghai New Excellent Medicine Talents Program (XYQ2011036) and Outstanding Doctoral Dissertation Author Fund of China (201131).

Affymetrix, E.T.P., and Cold Spring Harbor Laboratory, E.T.P. (2009). Post-transcriptional processing generates a diversity of 5'-modified long and short RNAs. Nature 457, 1028-1032.

Audas, T.E., Jacob, M.D., and Lee, S. (2012). Immobilization of proteins in the nucleolus by ribosomal intergenic spacer noncoding RNA. Mol Cell 45, 147-157.

Barry, G., Briggs, J.A., Vanichkina, D.P., Poth, E.M., Beveridge, N.J., Ratnu, V.S., Nayler, S.P., Nones, K., Hu, J., Bredy, T.W., Nakagawa, S., Rigo, F., Taft, R.J., Cairns, M.J., Blackshaw, S., Wolvetang, E.J., and Mattick, J.S. (2014). The long non-coding RNA Gomafu is acutely regulated in response to neuronal activation and involved in schizophrenia-associated alternative splicing. Mol Psychiatry 19, 486-494.

Batista, P.J., and Chang, H.Y. (2013). Long noncoding RNAs: cellular address codes in development and disease. Cell 152, 1298-1307. 
Bickmore, W.A. (2013). The spatial organization of the human genome. Annu Rev Genomics Hum Genet 14, 67-84.

Bond, C.S., and Fox, A.H. (2009). Paraspeckles: nuclear bodies built on long noncoding RNA. J Cell Biol 186, 637-644.

Chen, L.L., and Carmichael, G.G. (2009). Altered nuclear retention of mRNAs containing inverted repeats in human embryonic stem cells: functional role of a nuclear noncoding RNA. Mol Cell 35, 467-478.

Cheng, J., Kapranov, P., Drenkow, J., Dike, S., Brubaker, S., Patel, S., Long, J., Stern, D., Tammana, H., Helt, G., Sementchenko, V., Piccolboni, A., Bekiranov, S., Bailey, D.K., Ganesh, M., Ghosh, S., Bell, I., Gerhard, D.S., and Gingeras, T.R. (2005). Transcriptional maps of 10 human chromosomes at 5-nucleotide resolution. Science 308, 1149-1154.

Choudhry, H., Albukhari, A., Morotti, M., Hider, S., Moralli, D., Smythies, J., Schodel, J., Green, C.M., Camps, C., Buffa, F., Ratcliffe, P., Ragoussis, J., Harris, A.L., and Mole, D.R. (2014). Tumor hypoxia induces nuclear paraspeckle formation through HIF-2alpha dependent transcriptional activation of NEAT1 leading to cancer cell survival. Oncogene doi:10.1038/onc.2014.378.

Clemson, C.M., Hutchinson, J.N., Sara, S.A., Ensminger, A.W., Fox, A.H., Chess, A., and Lawrence, J.B. (2009). An architectural role for a nuclear noncoding RNA: NEAT1 RNA is essential for the structure of paraspeckles. Mol Cell 33, 717-726.

Consortium, E.P. (2012). An integrated encyclopedia of DNA elements in the human genome. Nature 489, 57-74.

Cremer, T., and Cremer, M. (2010). Chromosome territories. Cold Spring Harb Perspect Biol 2, a003889.

Cusanelli, E., and Chartrand, P. (2015). Telomeric repeat-containing RNA TERRA: a noncoding RNA connecting telomere biology to genome integrity. Front Genet 6, 143.

De Santa, F., Barozzi, I., Mietton, F., Ghisletti, S., Polletti, S., Tusi, B.K., Muller, H., Ragoussis, J., Wei, C.L., and Natoli, G. (2010). A large fraction of extragenic RNA pol II transcription sites overlap enhancers. PLoS Biol 8, e1000384.

Eissmann, M., Gutschner, T., Hammerle, M., Gunther, S., Caudron-Herger, M., Gross, M., Schirmacher, P., Rippe, K., Braun, T., Zornig, M., and Diederichs, S. (2012). Loss of the abundant nuclear non-coding RNA MALAT1 is compatible with life and development. RNA Biol 9, 1076-1087.

Engreitz, J.M., Pandya-Jones, A., McDonel, P., Shishkin, A., Sirokman, K., Surka, C., Kadri, S., Xing, J., Goren, A., Lander, E.S., Plath, K., and Guttman, M. (2013). The Xist lncRNA exploits three-dimensional genome architecture to spread across the X chromosome. Science 341 , 1237973

Fox, A.H., Bond, C.S., and Lamond, A.I. (2005). P54nrb forms a heterodimer with PSP1 that localizes to paraspeckles in an RNA-dependent manner. Mol Biol Cell 16, 5304-5315.

Fox, A.H., Lam, Y.W., Leung, A.K., Lyon, C.E., Andersen, J., Mann, M., and Lamond, A.I. (2002). Paraspeckles: a novel nuclear domain. Curr Biol 12, 13-25.

Fox, A.H., and Lamond, A.I. (2010). Paraspeckles. Cold Spring Harb Perspect Biol 2, a000687.

Gendrel, A.V., and Heard, E. (2014). Noncoding RNAs and epigenetic mechanisms during X-chromosome inactivation. Annu Rev Cell Dev Biol 30, 561-580.

Guru, S.C., Agarwal, S.K., Manickam, P., Olufemi, S.E., Crabtree, J.S., Weisemann, J.M., Kester, M.B., Kim, Y.S., Wang, Y., Emmert-Buck, M.R., Liotta, L.A., Spiegel, A.M., Boguski, M.S., Roe, B.A., Collins, F.S., Marx, S.J., Burns, L., and Chandrasekharappa, S.C. (1997). A transcript map for the $2.8-\mathrm{Mb}$ region containing the multiple endocrine neoplasia type 1 locus. Genome Res 7, 725-735.

Gutschner, T., Hammerle, M., and Diederichs, S. (2013a). MALAT1-a paradigm for long noncoding RNA function in cancer. J Mol Med (Berl) 91, 791-801.

Gutschner, T., Hammerle, M., Eissmann, M., Hsu, J., Kim, Y., Hung, G., Revenko, A., Arun, G., Stentrup, M., Gross, M., Zornig, M., MacLeod, A.R., Spector, D.L., and Diederichs, S. (2013b). The noncoding RNA MALAT1 is a critical regulator of the metastasis phenotype of lung cancer cells. Cancer Res 73, 1180-1189.
Guttman, M., and Rinn, J.L. (2012). Modular regulatory principles of large non-coding RNAs. Nature 482, 339-346.

Hacisuleyman, E., Goff, L.A., Trapnell, C., Williams, A., Henao-Mejia, J., Sun, L., McClanahan, P., Hendrickson, D.G., Sauvageau, M., Kelley, D.R., Morse, M., Engreitz, J., Lander, E.S., Guttman, M., Lodish, H.F., Flavell, R., Raj, A., and Rinn, J.L. (2014). Topological organization of multichromosomal regions by the long intergenic noncoding RNA Firre. Nat Struct Mol Biol 21, 198-206.

Hah, N., Benner, C., Chong, L.W., Yu, R.T., Downes, M., and Evans, R.M. (2015). Inflammation-sensitive super enhancers form domains of coordinately regulated enhancer RNAs. Proc Natl Acad Sci USA 112, E297-E302.

Hah, N., Murakami, S., Nagari, A., Danko, C.G., and Kraus, W.L. (2013). Enhancer transcripts mark active estrogen receptor binding sites. Genome Res 23, 1210-1223.

Hirose, T., Virnicchi, G., Tanigawa, A., Naganuma, T., Li, R., Kimura, H., Yokoi, T., Nakagawa, S., Benard, M., Fox, A.H., and Pierron, G. (2014). NEAT1 long noncoding RNA regulates transcription via protein sequestration within subnuclear bodies. Mol Biol Cell 25, 169-183.

Hutchinson, J.N., Ensminger, A.W., Clemson, C.M., Lynch, C.R., Lawrence, J.B., and Chess, A. (2007). A screen for nuclear transcripts identifies two linked noncoding RNAs associated with SC35 splicing domains. BMC Genomics 8, 39.

Ishii, N., Ozaki, K., Sato, H., Mizuno, H., Saito, S., Takahashi, A., Miyamoto, Y., Ikegawa, S., Kamatani, N., Hori, M., Saito, S., Nakamura, Y., and Tanaka, T. (2006). Identification of a novel non-coding RNA, MIAT, that confers risk of myocardial infarction. J Hum Genet 51, 1087-1099.

Jacob, M.D., Audas, T.E., Uniacke, J., Trinkle-Mulcahy, L., and Lee, S. (2013). Environmental cues induce a long noncoding RNA-dependent remodeling of the nucleolus. Mol Biol Cell 24, 2943-2953.

Ji, P., Diederichs, S., Wang, W., Boing, S., Metzger, R., Schneider, P.M., Tidow, N., Brandt, B., Buerger, H., Bulk, E., Thomas, M., Berdel, W.E., Serve, H., and Muller-Tidow, C. (2003). MALAT-1, a novel noncoding RNA, and thymosin beta4 predict metastasis and survival in early-stage non-small cell lung cancer. Oncogene 22, 8031-8041.

Ji, Q., Zhang, L., Liu, X., Zhou, L., Wang, W., Han, Z., Sui, H., Tang, Y., Wang, Y., Liu, N., Ren, J., Hou, F., and Li, Q. (2014). Long non-coding RNA MALAT1 promotes tumour growth and metastasis in colorectal cancer through binding to SFPQ and releasing oncogene PTBP2 from SFPQ/PTBP2 complex. Br J Cancer 111, 736-748.

Jiang, J., Jing, Y., Cost, G.J., Chiang, J.C., Kolpa, H.J., Cotton, A.M., Carone, D.M., Carone, B.R., Shivak, D.A., Guschin, D.Y., Pearl, J.R., Rebar, E.J., Byron, M., Gregory, P.D., Brown, C.J., Urnov, F.D., Hall, L.L., and Lawrence, J.B. (2013). Translating dosage compensation to trisomy 21. Nature 500, 296-300.

Kapranov, P., Cheng, J., Dike, S., Nix, D.A., Duttagupta, R., Willingham, A.T., Stadler, P.F., Hertel, J., Hackermuller, J., Hofacker, I.L., Bell, I., Cheung, E., Drenkow, J., Dumais, E., Patel, S., Helt, G., Ganesh, M., Ghosh, S., Piccolboni, A., Sementchenko, V., Tammana, H., and Gingeras, T.R. (2007). RNA maps reveal new RNA classes and a possible function for pervasive transcription. Science 316, 1484-1488.

Kim, T.K., Hemberg, M., Gray, J.M., Costa, A.M., Bear, D.M., Wu, J., Harmin, D.A., Laptewicz, M., Barbara-Haley, K., Kuersten, S., Markenscoff-Papadimitriou, E., Kuhl, D., Bito, H., Worley, P.F., Kreiman, G., and Greenberg, M.E. (2010). Widespread transcription at neuronal activity-regulated enhancers. Nature 465, 182-187.

Lai, F., Orom, U.A., Cesaroni, M., Beringer, M., Taatjes, D.J., Blobel, G.A., and Shiekhattar, R. (2013). Activating RNAs associate with Mediator to enhance chromatin architecture and transcription. Nature 494, 497-501.

Lazorthes, S., Vallot, C., Briois, S., Aguirrebengoa, M., Thuret, J.Y., St Laurent, G., Rougeulle, C., Kapranov, P., Mann, C., Trouche, D., and Nicolas, E. (2015). A vlincRNA participates in senescence maintenance by relieving $\mathrm{H} 2 \mathrm{AZ}-$ mediated repression at the INK4 locus. Nat Commun 6,5971 .

Lee, J.T. (2012). Epigenetic regulation by long noncoding RNAs. Science $338,1435-1439$.

Lee, J.T., and Jaenisch, R. (1997). Long-range cis effects of ectopic 
X-inactivation centres on a mouse autosome. Nature 386, 275-279.

Li, W., Notani, D., Ma, Q., Tanasa, B., Nunez, E., Chen, A.Y., Merkurjev, D., Zhang, J., Ohgi, K., Song, X., Oh, S., Kim, H.S., Glass, C.K., and Rosenfeld, M.G. (2013). Functional roles of enhancer RNAs for oestrogen-dependent transcriptional activation. Nature 498, 516-520.

Mao, Y.S., Sunwoo, H., Zhang, B., and Spector, D.L. (2011). Direct visualization of the co-transcriptional assembly of a nuclear body by noncoding RNAs. Nat Cell Biol 13, 95-101.

Nakagawa, S., Ip, J.Y., Shioi, G., Tripathi, V., Zong, X., Hirose, T., and Prasanth, K.V. (2012). Malat1 is not an essential component of nuclear speckles in mice. RNA 18, 1487-1499.

Nakagawa, S., Naganuma, T., Shioi, G., and Hirose, T. (2011). Paraspeckles are subpopulation-specific nuclear bodies that are not essential in mice. J Cell Biol 193, 31-39.

NE, I.I., Heward, J.A., Roux, B., Tsitsiou, E., Fenwick, P.S., Lenzi, L., Goodhead, I., Hertz-Fowler, C., Heger, A., Hall, N., Donnelly, L.E., Sims, D., and Lindsay, M.A. (2014). Long non-coding RNAs and enhancer RNAs regulate the lipopolysaccharide-induced inflammatory response in human monocytes. Nat Commun 5, 3979.

Nickerson, J.A., Krochmalnic, G., Wan, K.M., and Penman, S. (1989). Chromatin architecture and nuclear RNA. Proc Natl Acad Sci USA 86, 177-181

Nishimoto, Y., Nakagawa, S., Hirose, T., Okano, H.J., Takao, M., Shibata, S., Suyama, S., Kuwako, K., Imai, T., Murayama, S., Suzuki, N., and Okano, H. (2013). The long non-coding RNA nuclear-enriched abundant transcript 1_2 induces paraspeckle formation in the motor neuron during the early phase of amyotrophic lateral sclerosis. Mol Brain 6, 31 .

Okazaki, Y., Furuno, M., Kasukawa, T., Adachi, J., Bono, H., Kondo, S., Nikaido, I., Osato, N., Saito, R., Suzuki, H., Yamanaka, I., Kiyosawa, H., Yagi, K., Tomaru, Y., Hasegawa, Y., Nogami, A., Schonbach, C., Gojobori, T., Baldarelli, R., Hill, D.P., Bult, C., Hume, D.A., Quackenbush, J., Schriml, L.M., Kanapin, A., Matsuda, H., Batalov, S., Beisel, K.W., Blake, J.A., Bradt, D., Brusic, V., Chothia, C., Corbani, L.E., Cousins, S., Dalla, E., Dragani, T.A., Fletcher, C.F., Forrest, A., Frazer, K.S., Gaasterland, T., Gariboldi, M., Gissi, C., Godzik, A., Gough, J., Grimmond, S., Gustincich, S., Hirokawa, N., Jackson, I.J., Jarvis, E.D., Kanai, A., Kawaji, H., Kawasawa, Y., Kedzierski, R.M., King, B.L., Konagaya, A., Kurochkin, I.V., Lee, Y., Lenhard, B., Lyons, P.A., Maglott, D.R., Maltais, L., Marchionni, L., McKenzie, L., Miki, H., Nagashima, T., Numata, K., Okido, T., Pavan, W.J., Pertea, G., Pesole, G., Petrovsky, N., Pillai, R., Pontius, J.U., Qi, D., Ramachandran, S., Ravasi, T., Reed, J.C., Reed, D.J., Reid, J., Ring, B.Z., Ringwald, M., Sandelin, A., Schneider, C., Semple, C.A., Setou, M., Shimada, K., Sultana, R., Takenaka, Y., Taylor, M.S., Teasdale, R.D., Tomita, M., Verardo, R., Wagner, L., Wahlestedt, C., Wang, Y., Watanabe, Y., Wells, C., Wilming, L.G., Wynshaw-Boris, A., Yanagisawa, M., Yang, I., Yang, L., Yuan, Z., Zavolan, M., Zhu, Y., Zimmer, A., Carninci, P., Hayatsu, N., Hirozane-Kishikawa, T., Konno, H., Nakamura, M., Sakazume, N., Sato, K., Shiraki, T., Waki, K., Kawai, J., Aizawa, K., Arakawa, T., Fukuda, S., Hara, A., Hashizume, W., Imotani, K., Ishii, Y., Itoh, M., Kagawa, I., Miyazaki, A., Sakai, K., Sasaki, D., Shibata, K., Shinagawa, A., Yasunishi, A., Yoshino, M., Waterston, R., Lander, E.S., Rogers, J., Birney, E., Hayashizaki, Y., Consortium, F., I, R.G.E.R.G.P., and Team, I.I. (2002). Analysis of the mouse transcriptome based on functional annotation of 60,770 full-length cDNAs. Nature 420, 563-573.

Orom, U.A., Derrien, T., Beringer, M., Gumireddy, K., Gardini, A., Bussotti, G., Lai, F., Zytnicki, M., Notredame, C., Huang, Q., Guigo, R., and Shiekhattar, R. (2010). Long noncoding RNAs with enhancer-like function in human cells. Cell 143, 46-58.

Rapicavoli, N.A., Poth, E.M., and Blackshaw, S. (2010). The long noncoding RNA RNCR2 directs mouse retinal cell specification. BMC Dev Biol 10, 49.

Rinn, J.L., and Chang, H.Y. (2012). Genome regulation by long noncoding RNAs. Annu Rev Biochem 81, 145-166.

Sasaki, Y.T., Ideue, T., Sano, M., Mituyama, T., and Hirose, T. (2009). MENepsilon/beta noncoding RNAs are essential for structural integrity of nuclear paraspeckles. Proc Natl Acad Sci USA 106, 2525-2530.

Savic, N., Bar, D., Leone, S., Frommel, S.C., Weber, F.A., Vollenweider,
E., Ferrari, E., Ziegler, U., Kaech, A., Shakhova, O., Cinelli, P., and Santoro, R. (2014). lncRNA maturation to initiate heterochromatin formation in the nucleolus is required for exit from pluripotency in ESCs. Cell Stem Cell 15, 720-734.

Schaukowitch, K., Joo, J.Y., Liu, X., Watts, J.K., Martinez, C., and Kim, T.K. (2014). Enhancer RNA facilitates NELF release from immediate early genes. Mol Cell 56, 29-42.

Shen, W., Liang, X.H., and Crooke, S.T. (2014). Phosphorothioate oligonucleotides can displace NEAT1 RNA and form nuclear paraspeckle-like structures. Nucleic Acids Res 42, 8648-8662.

Shevtsov, S.P., and Dundr, M. (2011). Nucleation of nuclear bodies by RNA. Nat Cell Biol 13, 167-173.

Simon, M.D., Pinter, S.F., Fang, R., Sarma, K., Rutenberg-Schoenberg, M., Bowman, S.K., Kesner, B.A., Maier, V.K., Kingston, R.E., and Lee, J.T. (2013). High-resolution Xist binding maps reveal two-step spreading during X-chromosome inactivation. Nature 504, 465-469.

Sleeman, J.E., and Trinkle-Mulcahy, L. (2014). Nuclear bodies: new insights into assembly/dynamics and disease relevance. Curr Opin Cell Biol 28, 76-83.

Smeets, D., Markaki, Y., Schmid, V.J., Kraus, F., Tattermusch, A., Cerase, A., Sterr, M., Fiedler, S., Demmerle, J., Popken, J., Leonhardt, H., Brockdorff, N., Cremer, T., Schermelleh, L., and Cremer, M. (2014). Three-dimensional super-resolution microscopy of the inactive $\mathrm{X}$ chromosome territory reveals a collapse of its active nuclear compartment harboring distinct Xist RNA foci. Epigenet Chromat 7, 8.

Sone, M., Hayashi, T., Tarui, H., Agata, K., Takeichi, M., and Nakagawa, S. (2007). The mRNA-like noncoding RNA Gomafu constitutes a novel nuclear domain in a subset of neurons. J Cell Sci 120, 2498-2506.

Song, X., Shan, D., Chen, J., and Jing, Q. (2014). miRNAs and lncRNAs in vascular injury and remodeling. Sci China Life Sci 57, 826-835.

Souquere, S., Beauclair, G., Harper, F., Fox, A., and Pierron, G. (2010). Highly ordered spatial organization of the structural long noncoding NEAT1 RNAs within paraspeckle nuclear bodies. Mol Biol Cell 21, 4020-4027.

St Laurent, G., Savva, Y.A., and Kapranov, P. (2012). Dark matter RNA: an intelligent scaffold for the dynamic regulation of the nuclear information landscape. Front Genet 3, 57.

St Laurent, G., Shtokalo, D., Dong, B., Tackett, M.R., Fan, X., Lazorthes, S., Nicolas, E., Sang, N., Triche, T.J., McCaffrey, T.A., Xiao, W., and Kapranov, P. (2013). VlincRNAs controlled by retroviral elements are a hallmark of pluripotency and cancer. Genome Biol 14, R73.

Standaert, L., Adriaens, C., Radaelli, E., Van Keymeulen, A., Blanpain, C., Hirose, T., Nakagawa, S., and Marine, J.C. (2014). The long noncoding RNA Neat1 is required for mammary gland development and lactation. RNA 20, 1844-1849.

Sun, L., Goff, L.A., Trapnell, C., Alexander, R., Lo, K.A., Hacisuleyman, E., Sauvageau, M., Tazon-Vega, B., Kelley, D.R., Hendrickson, D.G., Yuan, B., Kellis, M., Lodish, H.F., and Rinn, J.L. (2013). Long noncoding RNAs regulate adipogenesis. Proc Natl Acad Sci USA 110, 3387-3392.

Sunwoo, H., Dinger, M.E., Wilusz, J.E., Amaral, P.P., Mattick, J.S., and Spector, D.L. (2009). MEN epsilon/beta nuclear-retained non-coding RNAs are up-regulated upon muscle differentiation and are essential components of paraspeckles. Genome Res 19, 347-359.

Tripathi, V., Ellis, J.D., Shen, Z., Song, D.Y., Pan, Q., Watt, A.T., Freier, S.M., Bennett, C.F., Sharma, A., Bubulya, P.A., Blencowe, B.J., Prasanth, S.G., and Prasanth, K.V. (2010). The nuclear-retained noncoding RNA MALAT1 regulates alternative splicing by modulating SR splicing factor phosphorylation. Mol Cell 39, 925-938.

Tripathi, V., Shen, Z., Chakraborty, A., Giri, S., Freier, S.M., Wu, X., Zhang, Y., Gorospe, M., Prasanth, S.G., Lal, A., and Prasanth, K.V. (2013). Long noncoding RNA MALAT1 controls cell cycle progression by regulating the expression of oncogenic transcription factor B-MYB. PLoS Genet 9, e1003368.

Tsuiji, H., Yoshimoto, R., Hasegawa, Y., Furuno, M., Yoshida, M., and Nakagawa, S. (2011). Competition between a noncoding exon and introns: Gomafu contains tandem UACUAAC repeats and associates with splicing factor-1. Genes Cells 16, 479-490. 
Ulitsky, I., Shkumatava, A., Jan, C.H., Sive, H., and Bartel, D.P. (2011). Conserved function of lincRNAs in vertebrate embryonic development despite rapid sequence evolution. Cell 147, 1537-1550.

Wang, D., Garcia-Bassets, I., Benner, C., Li, W., Su, X., Zhou, Y., Qiu, J., Liu, W., Kaikkonen, M.U., Ohgi, K.A., Glass, C.K., Rosenfeld, M.G., and Fu, X.D. (2011a). Reprogramming transcription by distinct classes of enhancers functionally defined by eRNA. Nature 474, 390-394.

Wang, K.C., Yang, Y.W., Liu, B., Sanyal, A., Corces-Zimmerman, R., Chen, Y., Lajoie, B.R., Protacio, A., Flynn, R.A., Gupta, R.A., Wysocka, J., Lei, M., Dekker, J., Helms, J.A., and Chang, H.Y. (2011b). A long noncoding RNA maintains active chromatin to coordinate homeotic gene expression. Nature 472, 120-124.

Wilusz, J.E., Freier, S.M., and Spector, D.L. (2008). 3' end processing of a long nuclear-retained noncoding RNA yields a tRNA-like cytoplasmic RNA. Cell 135, 919-932.

Xiang, J.F., Yin, Q.F., Chen, T., Zhang, Y., Zhang, X.O., Wu, Z., Zhang, S., Wang, H.B., Ge, J., Lu, X., Yang, L., and Chen, L.L. (2014). Human colorectal cancer-specific CCAT1-L lncRNA regulates long-range chromatin interactions at the MYC locus. Cell Res 24, 513-531.

Yin, Q.F., Hu, S.B., Xu, Y.F., Yang, L., Carmichael, G.G., and Chen, L.L. (2015). SnoVectors for nuclear expression of RNA. Nucleic Acids Res 43, e5.

Zhang, B., Arun, G., Mao, Y.S., Lazar, Z., Hung, G., Bhattacharjee, G., Xiao, X., Booth, C.J., Wu, J., Zhang, C., and Spector, D.L. (2012). The lncRNA Malat1 is dispensable for mouse development but its transcription plays a cis-regulatory role in the adult. Cell Rep 2, 111-123.

Zhang, H., Zeitz, M.J., Wang, H., Niu, B., Ge, S., Li, W., Cui, J., Wang, G., Qian, G., Higgins, M.J., Fan, X., Hoffman, A.R., and Hu, J.F. (2014). Long noncoding RNA-mediated intrachromosomal interactions promote imprinting at the Kcnq1 locus. J Cell Biol 204, 61-75.

Zhang, Y., Xie, S., Xu, H., and Qu, L. (2015). CLIP: viewing the RNA world from an RNA-protein interactome perspective. Sci China Life Sci $58,75-88$.

Zhu, J., Fu, H., Wu, Y., and Zheng, X. (2013). Function of IncRNAs and approaches to lncRNA-protein interactions. Sci China Life Sci 56, $876-885$.

Open Access This article is distributed under the terms of the Creative Commons Attribution License which permits any use, distribution, and reproduction in any medium, provided the original author(s) and source are credited. 